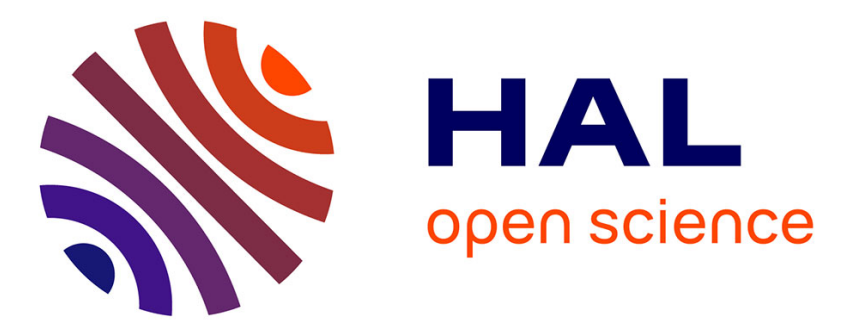

\title{
Simulation of the laser drilling process with the Constraint Natural Element Method
}

Jérémie Girardot, Lounes Illoul, Philippe Lorong, Nicolas Ranc, Mathieu

Schneider, Laurent Berthe, Véronique Favier

\section{To cite this version:}

Jérémie Girardot, Lounes Illoul, Philippe Lorong, Nicolas Ranc, Mathieu Schneider, et al.. Simulation of the laser drilling process with the Constraint Natural Element Method. ICALEO 2012, Sep 2012, Anaheim, CA, United States. pp.7. hal-01195824

\section{HAL Id: hal-01195824 \\ https://hal.science/hal-01195824}

Submitted on 8 Sep 2015

HAL is a multi-disciplinary open access archive for the deposit and dissemination of scientific research documents, whether they are published or not. The documents may come from teaching and research institutions in France or abroad, or from public or private research centers.
L'archive ouverte pluridisciplinaire HAL, est destinée au dépôt et à la diffusion de documents scientifiques de niveau recherche, publiés ou non, émanant des établissements d'enseignement et de recherche français ou étrangers, des laboratoires publics ou privés. 


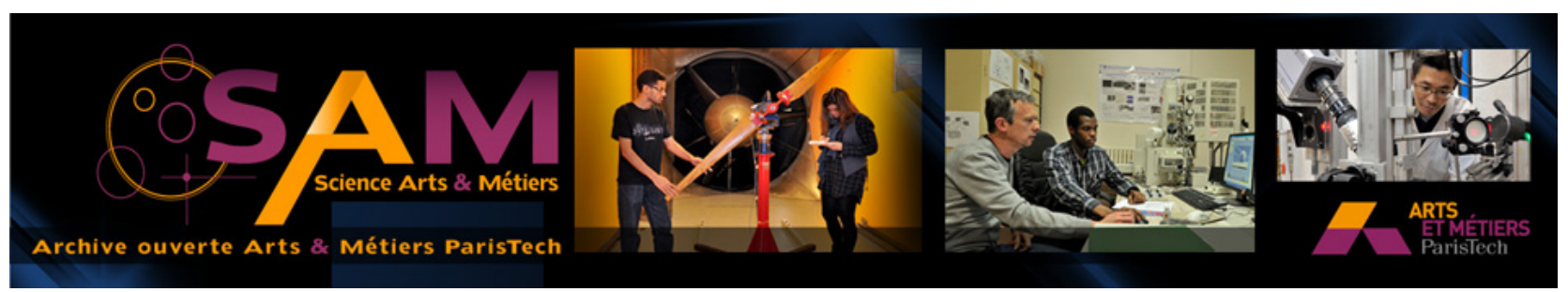

\section{Science Arts \& Métiers (SAM)}

is an open access repository that collects the work of Arts et Métiers ParisTech researchers and makes it freely available over the web where possible.

This is an author-deposited version published in: http://sam.ensam.eu

Handle ID: .http://hdl.handle.net/10985/9954

\section{To cite this version :}

Jérémie GIRARDOT, Lounes ILLOUL, Philippe LORONG, Nicolas RANC, Mathieu SCHNEIDER, Laurent BERTHE, Véronique FAVIER - Simulation of the laser drilling process with the Constraint Natural Element Method - In: ICALEO 2012, Etats-Unis, 2012-09-23 - Congress on Applications of Lasers \& Electro-Optics - 2012 


\title{
Simulation of the laser drilling process with the Constraint Natural Element Method
}

\author{
Paper \# 204
}

\author{
J. Girardot ${ }^{1}$, L. Illoul ${ }^{1}$, P. Lorong ${ }^{1}$, N. Ranc ${ }^{1}$, M. Schneider ${ }^{1}$, L. Berthe ${ }^{1}$, V. Favier ${ }^{1}$ \\ ${ }^{1}$ PIMM laboratory (CNRS), Arts et Metiers ParisTech \\ 151 Bd de l'Hôpital, 75013 Paris, France
}

\begin{abstract}
These works present a numerical alternative to the simulation of the laser drilling process. The use of the finite element method to modeling the hole creation during a laser pulse shows difficulties in front of a moving boundary problem. This moving boundary is induced by a fast phase transformation and also by high thermal gradient. The C-NEM (Constraint Natural Element Method) was tested in order to solve these numerical difficulties and to use the high potential of this original method. The physical interaction of the laser drilling will be reminded and the chosen mathematical model will be specified. A simulation was made with the data for pure iron in order to validate the numerical choice.
\end{abstract}

\section{Introduction}

The simulation of a machining process such as the laser drilling in percussion regime according to the process parameter is a challenge to predict the hole morphology and the induced effect on the drilled substrate. It would also allow better understanding the local phenomena occurring during the drilling such as the laser beam absorption. For a range of power density from 10 to $50 \mathrm{MW} . \mathrm{cm}^{-2}$, the main interaction between the focused laser beam and the substrate consists in heating the surface up to a high temperature. It is called 'percussion' a laser drilling with a static beam and a duration pulse about 1 millisecond. It induces the fusion and the vaporization of the material. The melt part is then ejected by the vapor pressure, creating the matter removal. This interaction acts all along the laser pulse and leads at the end to a hole. Many thermal exchanges between the laser beam, the moving liquid part and the solid part have to be taken into account in a simulation work. The Figure 1 shows the physical phenomena during a laser drilling in percussion regime.

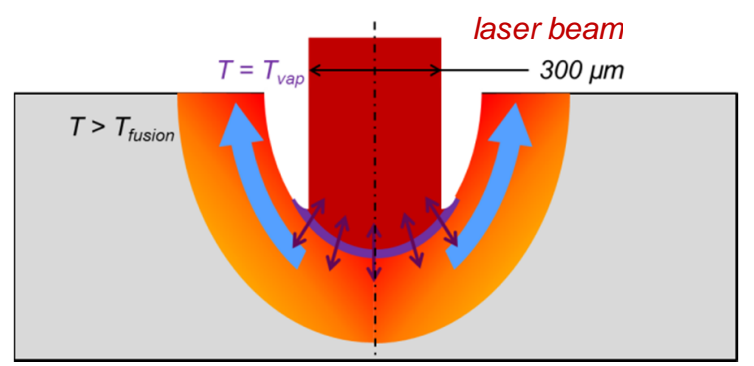

Figure 1: Schematic view of the drilling process

Many simulation works of the laser drilling were already proposed using calculation methods based on the finite element method and on methods to follow a free boundary and a moving interface. The "frontcapturing" methods as the level set or the VOF method relies on the employ of an implicit function to capture the interface position and is used in the work of [1] and [2]. The "front-tracking" methods as ALE method relies on following the free boundary with a moving mesh and is used in the work of [3] and [4]. These numerical choices induced some difficulties which minimize the results, especially because of the strain of the mesh and the volume representation of a boundary condition on the moving interfaces and free boundary [5].

This article presents a new approach of this calculation problem by the use of C-NEM (Constraint Natural Element Method [6]) method, which is halfway between meshless and the finite element method. It allows with a simple way and without high hypotheses to follow the liquid/solid and the liquid/vapor moving interface. It also makes easier the implementation of the heat equation and the Navier-Stokes equation. The non-linearity induced by the vaporization will be taken into account in the model. The first aim of this work is to propose a new numerical approach based on hypotheses and equations generally admitted in the FEM simulations.

First the physical model chosen for each domain is presented. Then, the C-NEM method is briefly explained before a discussion of the first results coming from the first simulations. 


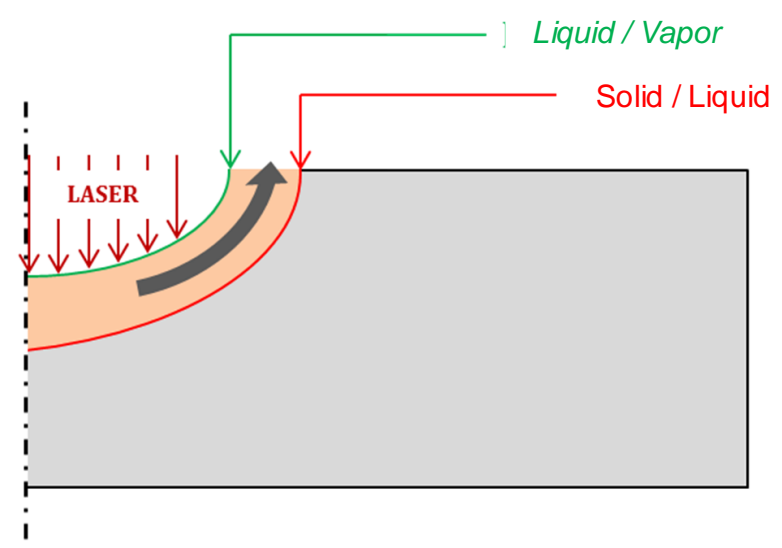

Figure 2: Computational domains and moving interfaces

\section{Physical model}

The model is based on an explicit boundary line between the solid and the liquid part (see Figure 2). The hypotheses for the computation are recalled below:

- The problem is a single shot of a laser beam on a homogeneous material. The axial symmetry is assumed ;

- Physical parameters are constant and not thermal dependent for gas, liquid and solid states ;

- The melt part ejected above the substrate as well as the vapored part are taking into account ;

- The heat flux applied on the free surface follows the spatial distribution of the laser beam which is a Gaussian. The time distribution follows the rampup of the laser source. The value of the intensity on the axis is equal to experimental measurements of the absorption following the work of Schneider \& al. in [7]. Thus, no absorptivity laws are implemented in the model ;

- The mechanical behavior of the melted part is incompressible and Newtonian ;

- The solid part is supposed rigid and only the thermal exchanges are considered;

- Surface tension phenomena on the free boundary are neglected.

\section{Solid domain}

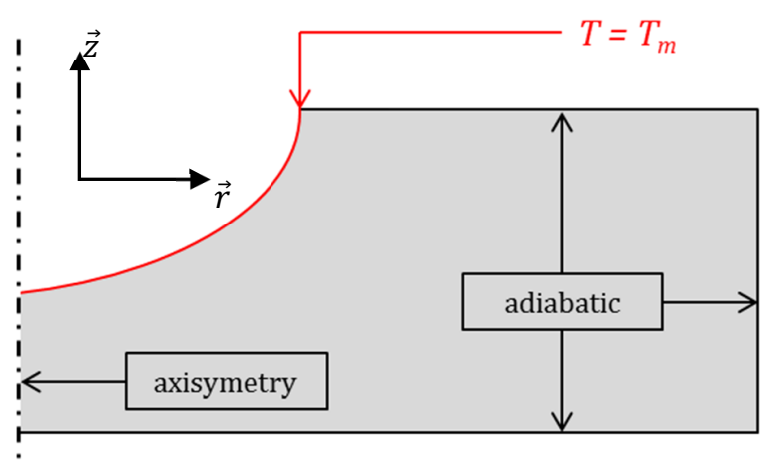

Figure 3: Computational domain in the solid

Exchanges in the solid part are described by the diffusion of the thermal energy with the heat equation:

$$
\rho_{s} C_{p_{s}} \frac{d T}{d t}=K_{s} \Delta T
$$

where $\rho_{s}, C_{p_{s}}$ and $K_{s}$ are respectively the density, the heat capacity and the thermal conductivity in the solid part. Boundary conditions applied to the domain are represented in the Figure 3:

- A temperature is set on the liquid/solid interface and equal to the melting point of the material $\mathrm{T}_{\mathrm{m}}$ :

$$
T=T_{m}
$$

- External boundaries are adiabatic :

$$
-K_{s} \overrightarrow{\nabla T} \cdot \vec{n}=0
$$

- An axisymmetric condition is set on the axis boundary:

$$
-K_{s} \overrightarrow{\nabla T} \cdot \vec{n}=0
$$

where $\vec{n}$ is the unit normal vector of the considered boundary. 


\section{Liquid domain}

\section{Conservative equations and boundary conditions}

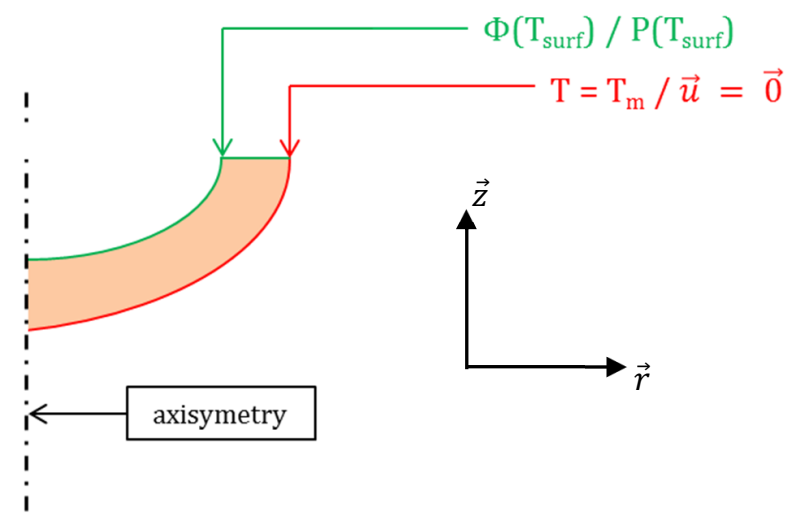

Figure 4

Figure 4: Computational domain in the liquid

Exchanges in the liquid part are described by the diffusion of the thermal energy with the heat equation and by the fluid movement with the Navier-Stokes equation and the mass conservation:

$$
\left\{\begin{array}{c}
\rho_{l} C_{p_{l}} \frac{d T}{d t}=K_{l} \Delta T \\
\rho_{l} \frac{d \vec{u}}{d t}=\operatorname{div}(\overline{\bar{\sigma}}) \\
\operatorname{div}(\vec{u})=0
\end{array}\right.
$$

where $\rho_{l}, C_{p_{l}}$ et $K_{l}$ are respectively the density, the heat capacity and the thermal conductivity in the liquid part. The behavior law of the fluid is

$$
\overline{\bar{\sigma}}=-p \overline{\bar{\delta}}+\mu\left(\overline{\overline{\nabla \vec{u}}}+\overline{\overline{\nabla \vec{u}}}^{T}\right)
$$

where $\mu$ is the dynamic viscosity of the melting part. Boundary conditions applied to the domain are represented in the Figure 4:

- A thermal flux $\Phi\left(T_{\text {surf }}\right)$. This value includes the absorbed intensity of the laser beam and the lost energy by vaporization, which explained the dependency of this term on the surface temperature $T_{\text {surf }}$ :

$$
-K_{l} \overrightarrow{\nabla T} \cdot \vec{n}=\Phi\left(T_{\text {surf }}\right)
$$

- A temperature is set on the liquid/solid interface and equal to the melting point of the material $\mathrm{T}_{\mathrm{m}}$ :

$$
T=T_{m}
$$

- An axisymmetric condition is set on the axis boundary:

$$
-K_{l} \overrightarrow{\nabla T} \cdot \vec{n}=0
$$

- A surface pressure induced by the local vaporization of the material with a temperature dependency is set on the free surface :

$$
p=P\left(T_{\text {surf }}\right)
$$

- The fluid is assumed fixed on the liquid/solid interface :

$$
\vec{u}=\overrightarrow{0}
$$

- An axisymmetric condition is set on the axis boundary:

$$
\left\{\begin{array}{c}
u_{r}=0 \\
\frac{\partial u_{z}}{\partial r}=0
\end{array}\right.
$$

\section{Multiphysic coupling on the free surface}

The thermo-mechanical coupling as the temperature dependency of the viscosity, the density or the thermal conductivity is not taken into account in this model. These couplings are not the highest numerical difficulties of the global computation. Indeed, the laser drilling process is controlled by the free surface temperature. Thus, the real heat flux applied to the surface has a temperature dependency because of the energy loss by the vaporization. The Hertz-Langmuir equation coupled with the Clapeyron equation is generally set to model this coupling. This relation is after adiabatic atomic density conservation on a small element on the vaporized free surface and gives the flow of vaporized matter. The Clapeyron equation gives the equilibrium vapor pressure as a function of surface temperature. The backscattering phenomenon due to a recondensation into the Knudsen layer, [8] and [9], is also included in the coupling with the $\beta_{r}$ coefficient [10] and [11]. The heat flux becomes:

$$
\phi\left(T_{\text {surf }}\right)=\phi_{\text {laser }}-L_{v} \dot{M}_{\text {vap }}\left(1-\beta_{r}\right)
$$

where

$$
\dot{M}_{\text {vap }}=\left[\sqrt{\frac{m}{2 \pi k_{B}}} \frac{P_{a t m} \exp \left(\frac{M_{a} L_{v}}{R}\left(\frac{1}{T_{v}}-\frac{1}{T_{\text {surf }}}\right)\right)}{\sqrt{T_{\text {surf }}}}\right]
$$

The back pressure applied to the free surface has therefore and temperature dependency described in the model by the Clapeyron equation. The backscattering effect which increases the local pressure is also 
included with the $\beta_{r}$ coefficient. The reader could also remark the surface pressure is decrease of the atmospheric pressure following the discussion of [12] :

$$
P\left(T_{\text {surf }}\right)=\left[P_{\text {atm }} \exp \left(\frac{M_{a} L_{v}}{R}\left(\frac{1}{T_{v}}-\frac{1}{T_{\text {surf }}}\right)\right)-P_{\text {atm }}\right]\left(\frac{1+\beta_{r}}{2}\right)
$$

Physical terms are described in the following Table 1:

\begin{tabular}{|c|c|c|}
\hline$\phi_{\text {laser }}$ & Absorbed laser intensity & W. $\mathrm{m}^{-2}$ \\
\hline$\beta_{r}$ & Retrodiffusion coefficient & - \\
\hline$M_{a}$ & Atomic mass & $\mathrm{kg}$ \\
\hline$L_{v}$ & Latent heat of vaporization & $\mathrm{J}^{\mathrm{kg}}{ }^{-1}$ \\
\hline$T_{v}$ & Vapor point at ambient pressure & $\mathrm{K}^{\circ}$ \\
\hline $\mathrm{m}$ & Molar mass & $\mathrm{kg} \cdot \mathrm{mol}^{-1}$ \\
\hline$k_{B}$ & Boltzmann constant & $\mathrm{m}^{2} \cdot \mathrm{kg} \cdot \mathrm{s}^{-2} \cdot \mathrm{K}^{-1}$ \\
\hline $\mathrm{R}$ & Ideal gas constant & $\mathrm{J} \cdot \mathrm{mol}^{-1} \cdot \mathrm{K}^{-1}$ \\
\hline$P_{a t m}$ & Atmospheric pressure & $\mathrm{Pa}$ \\
\hline
\end{tabular}

Table 1: Physical terms used in equations

\section{$\underline{\text { Moving interfaces }}$}

The numerical choice in the model is especially to handle the difficulties to follow the melting front and the free surface. It will be briefly discussed in the next chapter.

This model supposes a non-scattered melting front described by the Stefan relation. This equation is after an energy balance at the interface with the thermal loss from each side and with the heat latent of fusion $L_{m}$. The melting front velocity $\overrightarrow{V_{m}}$ is:

$$
\overrightarrow{V_{m}}=\frac{1}{\rho_{s} L_{m}}\left[\left(K_{l} \overrightarrow{\nabla T_{l}}-K_{S} \overrightarrow{\nabla T_{s}}\right) \cdot \vec{n}\right] \cdot \vec{n}
$$

The vaporizing front velocity is composed of two terms corresponding to 1 ): the mechanical digging due to the liquid ejection, 2): the loss of vaporized mass. The first term is the surface velocity being after the Navier-Stokes equation and the second term is after the vaporized mass flow given by the Hertz-Langmuir relation. The vaporizing front velocity $\overrightarrow{V_{v}}$ is:

$$
\overrightarrow{V_{v}}=\overrightarrow{u_{\text {surf }}}+\frac{\dot{M}_{v a p}}{\rho_{l}} \vec{n}
$$

\section{Numerical implementation}

\section{Spatial C-NEM Discretization}

The C-NEM method (Constraint Natural Element Method) is an alternative technic to the finite element method [6] \& [13]. It is an update to the NEM method for non-convex domains [14] benefits from two assets used in the implementation of the last equations in the model:

(1) The field interpolation is defined in any point thanks to information provided by the natural neighbors' nodes. This interpolation is not dependent of the mesh quality. Thus, balance equations written in a lagrangian formulation which leads to move nodes, will not induced any mesh distortion in the liquid domain. Indeed, only the moving domain is written in a lagrangian formulation. About the fluid mechanic, the reader could refer to the works of [5], who use an "updated-lagrangian formulation";

(2) Moving discontinuities can be inserted in a fixed mesh cloud, by inserting or suppressing a new intern boundary. The works of [15] deal with the simulation of a melting front propagation using this method.

\section{Implementation details}

Times derivatives are discretized by an implicit finite difference scheme. Considered a filed $V$, the time derivative between the time $n$ and $n+1$ becomes:

$$
\left(\frac{d V}{d t}\right)^{n+1}=\frac{V^{n+1}-V^{n}}{\Delta t}
$$

where $\Delta t$ is the considered time step

The coupling on the boundary free surface corresponding to loss heat flux in the liquid domain leads to a non-linearity of the problem in the heat equation. Its solving is made thanks to a simple substitution method which converges after less than three iterations. The convergence criterion is less than 0.01 Kelvin.

Physical properties of liquid phase and solid phase are taken from pure iron and the iteration procedure is defined as:

1) Discretization of the two liquid and solid domains, constrained by the melting front interface;

2) Computation of thermal fields in each domains and obtaining the surface back pressure; 
3) Computation of the velocity field in the liquid domain;

4) Determination of $\overrightarrow{V_{m}}$ and $\overrightarrow{V_{v}}$;

5) Updating of the two domains thanks to : the velocity of the melting front, the velocity of the free surface and the melting part velocity field.

\section{Results}

For this first approach, the calculation was made until $13,6 \mu \mathrm{s}$ for a $1 \mathrm{~ms}$ laser pulse. The aim is to describe the beginning of the drilling when the transitional terms are the most important. First results well confirm the relevance of the C-NEM choice compared with the FEM. The Figure 5 shows the temperature filed with velocity arrows for six calculation times. It is noticeable that the liquid ejection is no more included in the calculation beyond a certain threshold and the velocity field takes a nonzero value only in the melting part. The absorbed flux magnitude is $13 \mathrm{MW} . \mathrm{cm}^{-2}$. Values of surface temperature, melting thickness and ejection speed are of the same order of magnitude than those which can be found in the experimental work of [16].

The Figure 6 shows for the same calculation times the node density in the ejection area. Some remarks can be made:

- Liquid and solid domains are geometrically distinct at each step. The liquid/solid interface as the freesurface is described by an explicit nodal boundary.

- The updated lagrangian formulation in the liquid domain induces a very heterogeneous repartition because of moving nodes following the velocity field. Despite, the solution is not compromised by it.

- The followed melting front also does not impact on the final solution.

\section{Conclusion}

A new numerical method was tested in a laser drilling simulation work. First results validate the choice and especially make easier the track of a moving interface as a free-boundary.

An updated lagrangian formulation was implemented to abstain from instabilities problem due to an advection terms in the heat and Navier-Stokes equations. Moving nodes due to this formulation do not impact on the final solution.

Give last results, numerical implementation of the laser drilling model is yet accomplished. The computation has now to be tested until a $1 \mathrm{~ms}$ laser pulse in real conditions. Results will be then compared to experimental measurements at our disposal as the hole geometries (depth, width, generalized profiles, recast thickness layer...) and as melting ejection velocity. It will allow to discuss the validity of hypothesis and to better understand the thermal properties influence for a laser drilling. 

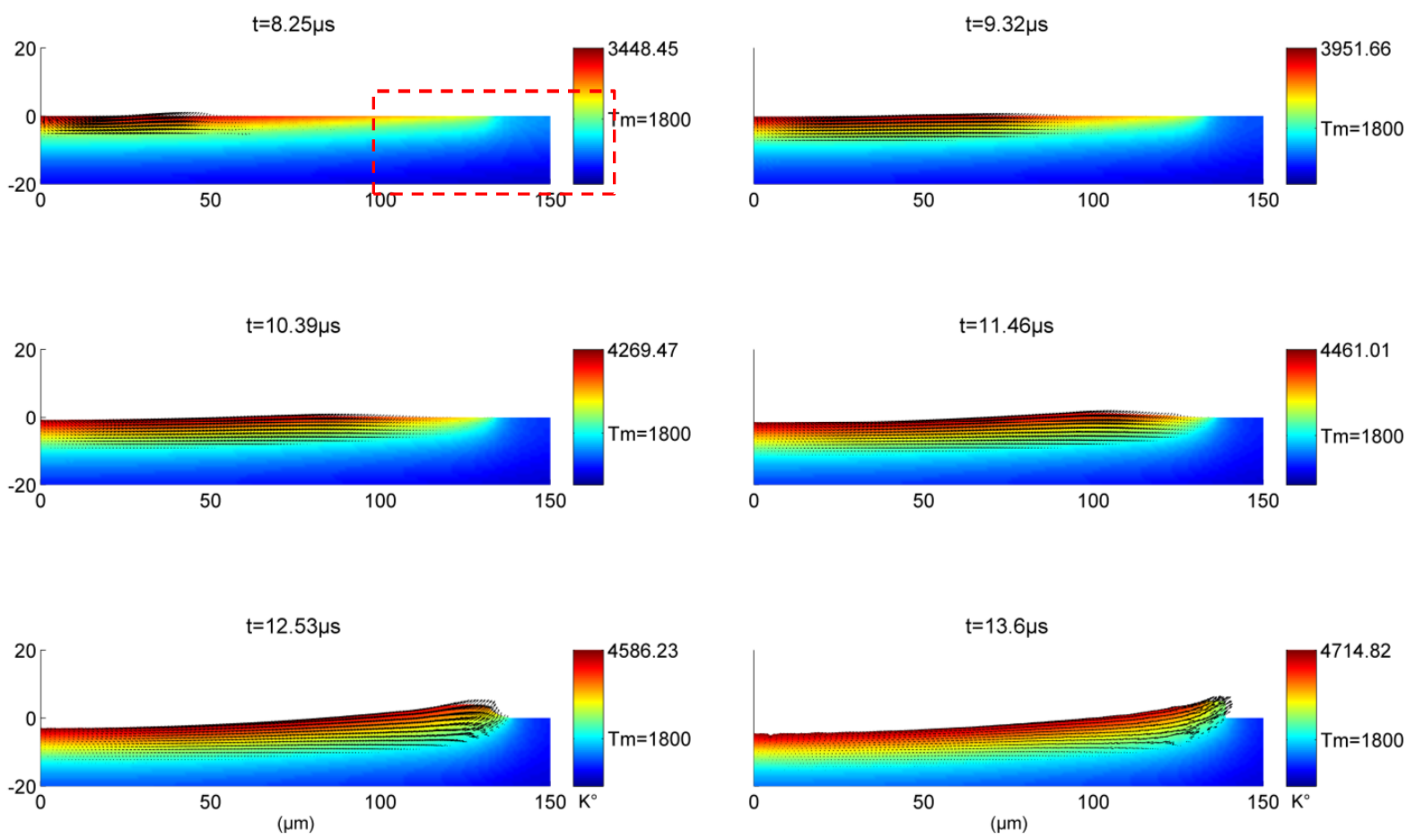

Figure 5: Temperature field $\left(\mathrm{K}^{\circ}\right)$, Arrows: liquid velocity

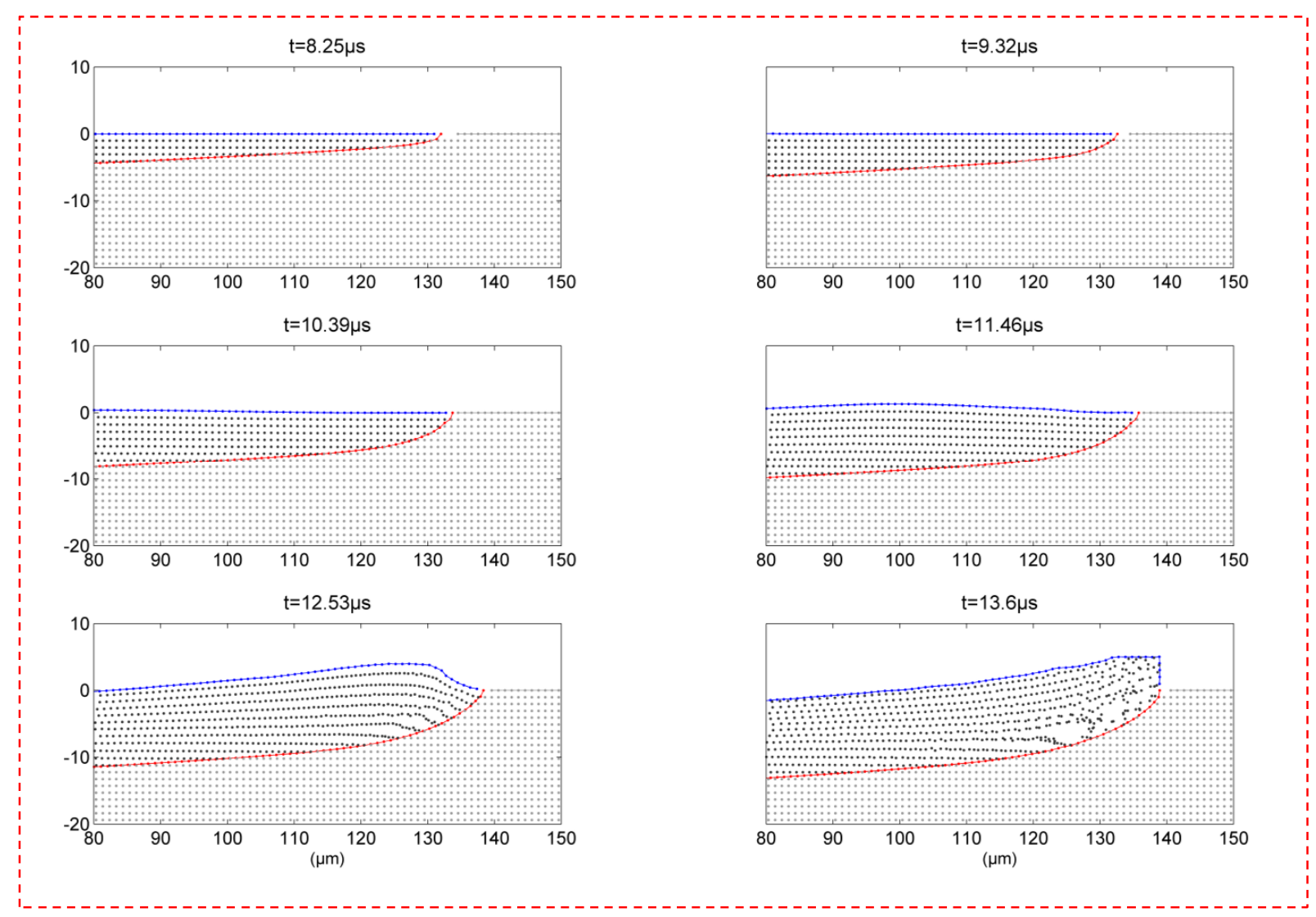

Figure 6: Node repartition in each domain 


\section{References}

[1] H. Ki, P. S. Mohanty and M. J., "Modelling of high-density laser material interaction using level set method," Journal of physics D : Applied Physics, vol. 34, pp. 364-372, 2000.

[2] Z. Ge, G. Yu, K. He, G. Lu et L. S., «Three dimensional transient numerical simulation of gaussian laser beam drilling process,» Proceedings of the 23rd ICTAM, 2012.

[3] N. Revuz, «Etude de l'endommagement d'un superalliage monocristallin à base de nickel induit par perçage laser,» Thesis manuscript, Engineering school of Mines ParisTech, 2010.

[4] D. F. de Lange, A. Schoonderbeek et M. J., «Melt ejection during laser drilling,» Proceedings of the 23rd ICALEO, 2004.

[5] D. Gonzales, E. Cueto, F. Chinesta et M. Doblaré, «A natural element updated lagrangian strategy for free surface fluid dynamics,» Journal of computational physics, vol. 223, pp. 127-150, 2007.

[6] F. Chinesta, S. Cescotto, E. Cueto et P. Lorong, Natural Element Method for the simulation of the structures and processe, Wiley, 2011.

[7] M. Schneider, L. Berthe, R. Fabbro et M. Muller, «Measurement of laser absorptivity for operating parameters characteristic of laser drilling regime,» Journal of physics D: Applied Physics, vol. 41, $\mathrm{n}^{\circ} \% 1155502,2008$.

[8] A. A. Samokhin, «First-order phase transitions induced by laser radiation in absorbing condensed matter,» Proceedings of the Institute of General Physics, vol. 13, pp. 1-161, 1990.

[9] T. Ytrehus et S. Ostmo, «Kinetic theory approach to interphase processes,» Int. Journal of Multiphase flow, vol. 22, pp. 133-155, 1996.

[10] C. J. Knight, «Theoretical modelling of rapide surface vaporization with back pressure,» AIAA Journal, vol. 17, pp. 78-1220, 1979.
[11] C. Mas, «Modélisation du procédé de découpe de métaux par laser,» Thesis manuscript, french university of Paris 6, 2003.

[12] K. Hirano, R. Fabbro et M. Muller, «Experimental determination of temperatrue threshold for melt surface deformation during laser interaction on iron at atmosphere pressure,» Journal of Physics D : Applied Physics, vol. 44, p. 435402, 2011.

[13] J. Yvonnet, «Nouvelles approches sans maillage basées sur la méthode des éléments naturels pour la simulation numérique des procédés de mise en forme,» Thesis manuscript, Engineering school of Arts et Métiers ParisTech, 2004.

[14] J. Yvonnet, D. Ryckelynck, P. Lorong and F. Chinesta, "A new extension of the natural element method for non-convex and discontinuous problems : the constrained natural element method (C-NEM)," Int. J. for numerical methods in engineering, vol. 60, pp. 1451-1474, 2004.

[15] J. Yvonnet, F. Chinesta, P. Lorong et D. Ryckelynck, «The constraint natural element method (C-NEM) for treating htemrla models involving moving interfaces,» Int. J. of thermal sciences, vol. 44, pp. 559-569, 2005.

[16] M. Schneider, J. Girardot et L. Berthe, «Recoil pressure and surface temperature in laser drilling,» Proceedings in the 30th ICALEO, 2011. 